\title{
Intrinsic adriamycin resistance in p53-mutated breast cancer is related to the miR-30c/FANCF/ REV1-mediated DNA damage response
}

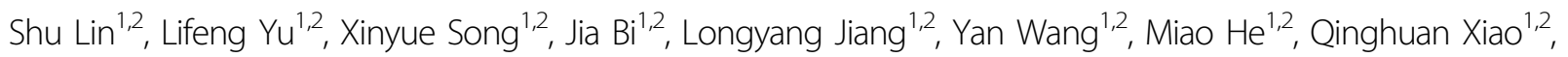
Mingli Sun ${ }^{1,2}$, Olufunmilayo I. Olopade ${ }^{3}$, Lin Zhao ${ }^{1,2}$ and Minjie Wei ${ }^{1}$

\begin{abstract}
Adriamycin(ADR) is still considered to be one of the most effective agents in the treatment of breast cancer (BrCa), its efficacy is compromised by intrinsic resistance or acquire characteristics of multidrug resistance. At present, there are few genetic alterations that can be exploited as biomarkers to guide targeted use of ADR in clinical. Therefore, exploring the determinants of ADR sensitivity is pertinent for their optimal clinical application. TP53 is the most frequently mutated gene in human BrCa, p53 mutation has been reported to be closely related to ADR resistance, whereas the underlying mechanisms that cause endogenous ADR resistance in p53-mutant BrCa cells are not completely understood. The aim of the present study was to investigate the potential roles of miRNA in the response to ADR in p53-mutated breast cancer. Here, we report that BrCa cells expressing mutp53 are more resistant to ADR than cells with wild-type p53 (wtp53). The DNA repair protein- Fanconi anemia complementation group F protein (FANCF) and the translesion synthesis DNA polymerase REV1 protein is frequently abundant in the context of mutant p53 of BrCa. By targeting two key factors, miR-30c increases the sensitivity of BrCa cells to ADR. Furthermore, p53 directly activates the transcription of miR-30c by binding to its promoter. Subsequent analyses revealed that p53 regulates REV1 and FANCF by modulating miR-30c expression. Mutation of the p53 abolished this response. Consistently, reduced miR-30c expression is highly correlated with human BrCa with p53 mutational status and is associated with poor survival. We propose that one of the pathways affected by mutant p53 to increase intrinsic resistance to ADR involves miR-30c downregulation and the consequent upregulation of FANCF and REV1. The novel miRNA-mediated pathway that regulates chemoresistance in breast cancer will facilitate the development of novel therapeutic strategies.
\end{abstract}

\section{Introduction}

Breast cancer is the most commonly diagnosed cancer in women and the fifth leading cause of cancer-related death worldwide, despite recent advances in therapeutic

\footnotetext{
Correspondence: Lin Zhao (zl_cmu@163.com) or Minjie Wei (mjwei@cmu.edu.cn) 'Department of Pharmacology, School of Pharmacy, China Medical University, No. 77 Puhe Road, Shenyang North New Area, 110122 Shenyang City, Liaoning, China ${ }^{2}$ Liaoning Key Laboratory of molecular targeted anti-tumor drug development and evaluation, China Medical University, No.77 Puhe Road, Shenyang North New Area, 110122 Shenyang City, Liaoning, China

Full list of author information is available at the end of the article.

These authors contributed equally: Shu Lin, Lifeng Yu

Edited by I. Amelio
}

options $^{1}$. ADR is considered one of the most effective agents for the treatment of $\mathrm{BrCa}$, particularly following tamoxifen failure, but its efficacy as a curative agent is compromised by intrinsic resistance and the acquisition of multidrug resistance characteristics during chemotherapy ${ }^{2}$.In general, prognostic factors are helpful for better individual risk stratification and clinical outcome prediction. At present, few genetic alterations have been identified that can be exploited as biomarkers to guide the targeted use of ADR clinically. Therefore, exploring the determinants of ADR sensitivity is pertinent for their optimal clinical application.

\section{(c) The Author(s) 2019}

(c) (i) Open Access This article is licensed under a Creative Commons Attribution 4.0 International License, which permits use, sharing, adaptation, distribution and reproduction cc) in any medium or format, as long as you give appropriate credit to the original author(s) and the source, provide a link to the Creative Commons license, and indicate if changes were made. The images or other third party material in this article are included in the article's Creative Commons license, unless indicated otherwise in a credit line to the material. If material is not included in the article's Creative Commons license and your intended use is not permitted by statutory regulation or exceeds the permitted use, you will need to obtain permission directly from the copyright holder. To view a copy of this license, visit http://creativecommons.org/licenses/by/4.0/. 
In addition to chemotherapeutic agents, genotypic changes play a decisive role in determining the fate of cancer cells after exposure to chemotherapeutic agents. TP53 is the most frequently altered gene in human cancers $^{3}$. Missense mutp53 protein(s) are very stable, and they acquire oncogenic properties that increase metastasis, proliferation, and cell survival ${ }^{4}$. p53 mutations also contribute to resistance to a variety of standard chemotherapies. A correlation between the expression of mutant p53 and resistance to ADR therapy has been observed in $\mathrm{BrCa}$ patients ${ }^{5,6}$. Identifying the signaling pathways that participate with mutp53 to promote BC chemotherapy resistance is a rational approach to unmask candidate drug targets.

ADR causes DNA damage, triggering cells to activate their DNA damage repair machinery. Deficiency in the proteins involved in DNA damage repair is considered a major determinant of the response to chemotherapy in cancer cells ${ }^{7,8}$. Proteome-wide analysis of mutp53 targets in $\mathrm{BrCa}$ identified new gain-of-function mutants, some of which involved DNA repair-related proteins ${ }^{5,6,9}$. However, little is known about DNA repair during the development and treatment of breast tumors with p53 mutations. Therefore, extensive investigations on the DNA repair functions that are deregulated with intrinsic ADR resistance in p53-mutated $\mathrm{BrCa}$ are required.

Currently, there is a growing interest in the therapeutic potential of strategies aimed to target microRNA (miRNA) networks. In the past decade, miRNAs were identified as a novel class of pivotal regulators of gene expression by base pairing with the 3 '-untranslated region (UTR) of target mRNAs ${ }^{10}$. As each miRNA can control hundreds of gene targets, we explored the possibility that miRNAs simultaneously target deregulated DNA repair proteins in p53-mutated, ADRresistant $\mathrm{BrCa}$.

Here, we uncovered the mechanism of resistance to ADR in p53-mutated $\mathrm{BrCa}$, which involves the miRNAmediated regulation of the DNA repair protein FANCF and the translesion synthesis DNA polymerase REV1. Specifically, we identified a miRNA, miR-30c, that regulates the expression of FANCF and REV1 and specifically suppresses DNA damage repair. Consistent with these effects, overexpression of miR-30c enhanced breast cancer chemosensitivity to ADR in p53-mutant $\mathrm{BrCa}$ cells. Furthermore, reduced miR-30c expression was highly correlated with human $\mathrm{BrCa}$ p53 mutational status and was associated with poor survival, suggesting its direct clinical relevance in patients with $\mathrm{BrCa}$. Our findings highlight the functions and roles of miRNAs in $\mathrm{BrCa}$ and suggest that resistance to ADR in p53-mutant $\mathrm{BrCa}$ may be related to miR-30c/FANCF/REV1-mediated DNA damage response.

\section{Results}

ADR resistance in p53-mutated BrCa cells is related to the high expression of FANCF and REV1

To determine whether p53 status can affect the survival of $\mathrm{BrCa}$ cells upon ADR treatment, we first evaluated and compared the ADR sensitivity of a panel of $\mathrm{BrCa}$ cell lines with known p53 status. We found that cells expressing mutp53 (MDA-MB-231 and T-47D) were significantly more resistant to ADR than cells expressing wtp53 (MCF10A, MCF-7, and ZR-75-1) (Fig. 1a, b). Strikingly, introducing the mutp53 R280K into wtp53 MCF-7 and ZR-751 cells reduced their ADR sensitivity (Fig. 1c). In contrast, the restoration of p53 expression sensitized the p53mutated MDA-MB-231 and T-47D cells to ADR (Fig. 1d).

Because DNA damage repair is one of the main mechanisms that affects the efficacy of chemotherapy, to define a mechanism of action for mutp53 in the response to ADR, we first compared the differences in DNA damage between p53 wt vs. p53 mut-type BrCa cells. We found that MCF-7 cells expressing wtp53 had significantly more residual DNA DSBs than MDA-MB-231 cells expressing mutp53 cells, as evidenced by the increased signal intensity of $\gamma-\mathrm{H} 2 \mathrm{AX}$ staining and by the increase in comet tail moments (Fig. 1e). We next compared the expression of DNA repair pathway proteins in p53mutated and p53-wt cell lines, and those with p53 mutations showed significantly increased levels of FANCF, REV1, RAD51, BRCA1, ATM, and ERCC1 compared to those of the p53 wild-type cell lines (Fig. 1f) and other genes including FANCM, ERCC4, RAD52, and REV3 have no significant differences (Supplementary Fig. S1). We subsequently focused on FANCF and REV1, the proteins with the most increased expression levels in the p53-mutant cell lines. Additionally, reduced levels of FANCF and REV1 were detected in ADR-treated MCF-7 cells but not in MDA-MB-231 cells (Fig. 1g), and the effect was largely impeded in p53-R280K-expressing cells (Fig. 1h). These data suggested that increased FANCF and REV1 levels may represent a molecular determinant for ADR resistance in p53-mutant cell lines.

\section{miR-30c inhibits FANCF and REV1 expression by targeting their $3^{\prime}$-UTRs}

Since ADR resistance in p53-mutated $\mathrm{BrCa}$ cells is related to the high expression of FANCF and REV1, we used online databases (TargetScan, RNA2 and RNAhybrid) to screen for miRNAs that simultaneously target the 3'-UTRs of the FANCF and REV1 mRNAs. Only the miR30 family (including miR-30a, miR-30b, miR-30c, miR$30 \mathrm{~d}$ and miR-30e) contained putative binding sites for FANCF and REV1 (Supplementary Fig. S2ab). The minimum free energy between miR-30 and the putative binding sites in the $3^{\prime}$-UTRs of the REV1 and FANCF mRNAs suggested that miR-30 may target REV1 and 


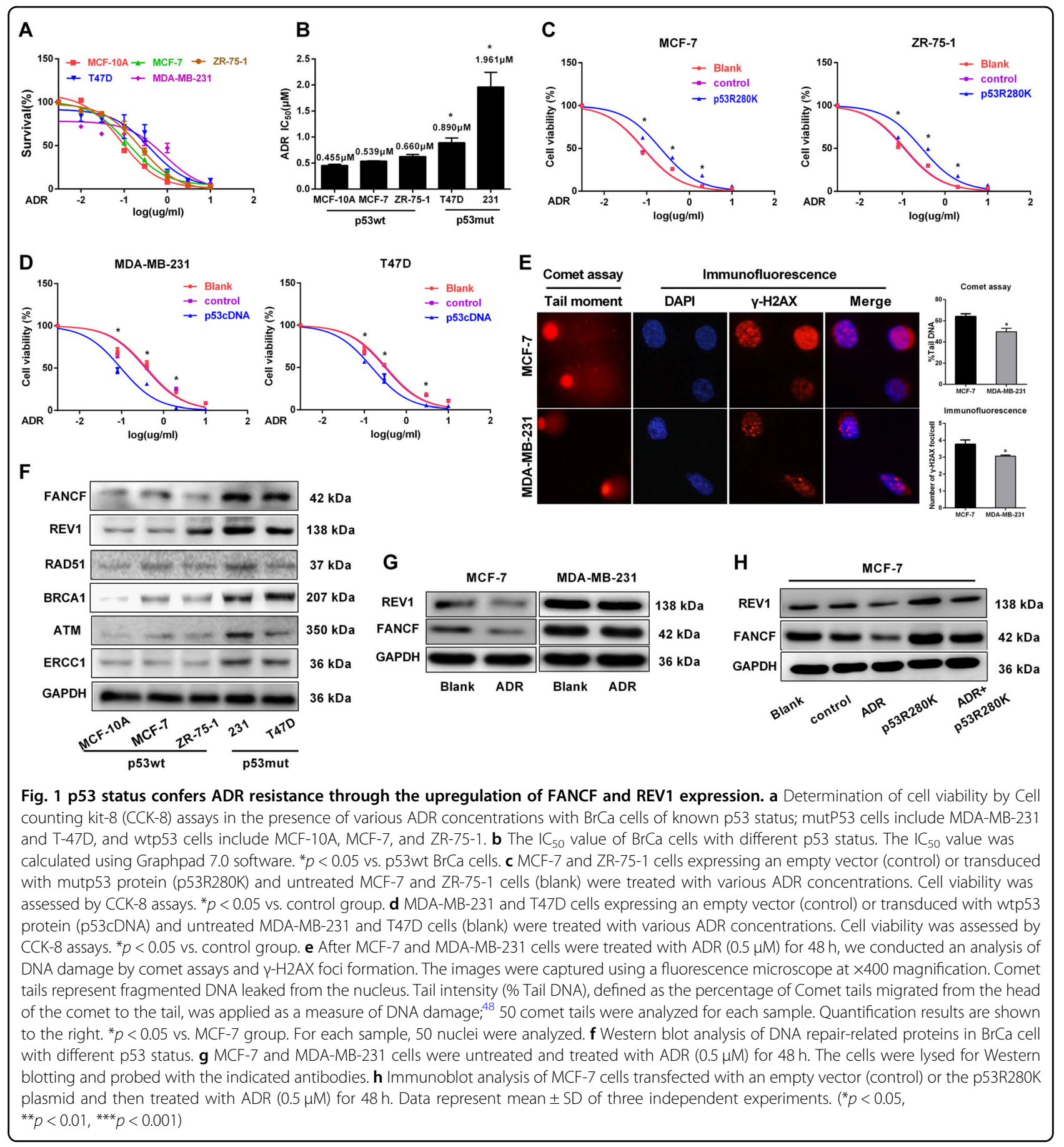

FANCF (Supplementary Fig. S2c). We then detected the expression of REV1 and FANCF in MCF-7 and MDAMB-231 cells transfected with miR-30 family miRNAs using qRT-PCR and Western blot analyses. The expression levels of REV1 and FANCF were significantly decreased in cells overexpressing miR-30 family miRNAs, and miR-30c produced the strongest effect (Fig. 2a, b). Furthermore, luciferase activity assays showed that miR$30 \mathrm{c}$ overexpression significantly reduced luciferase activity in cells transfected with the wild-type pGL3REV1-3'UTR-Full and pGL3-FANCF-3'UTR-Full vectors. Mutations in the putative binding sites in the $3^{\prime}$-UTRs of the REV1 and FANCF mRNAs abolished the inhibitory effect of miR-30c on luciferase activity (Fig. 2c, d). The inhibition of endogenous miR-30c by miR-30c inhibitors increased the mRNA (Supplementary Fig. S3) and protein expression (Fig. 2e) of REV1 and FANCF in BrCa cells. miR-30c inhibitors also increased the expression of 


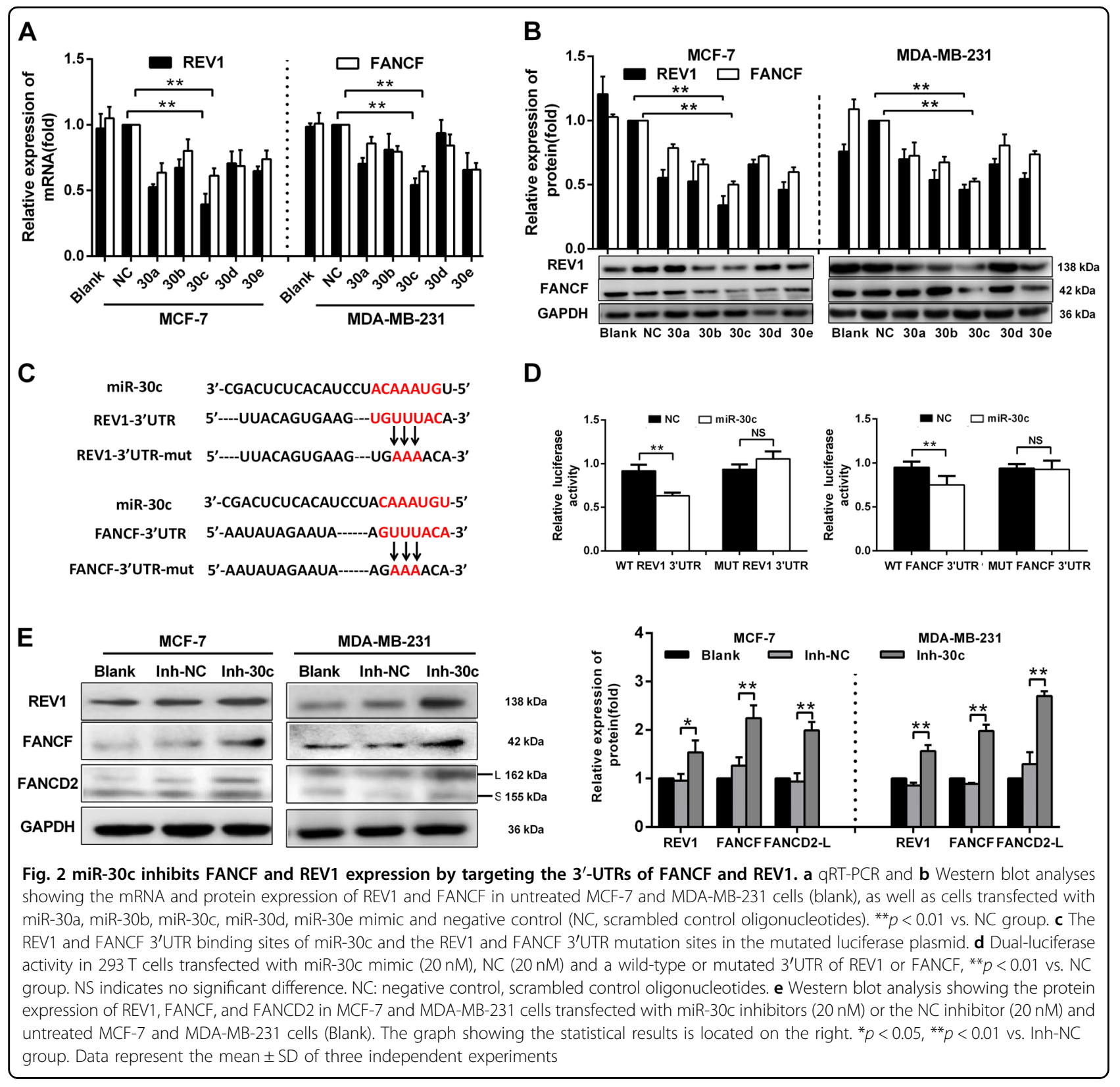

FANCD2-L (the monoubiquitylated isoform) and FANCD2-S (the primary unmodified translation product), which activates the FA/BRCA pathway ${ }^{11}$ (Fig. 2e). These results suggested that miR-30c directly targets REV1 and FANCF via the putative binding sites in the 3 '-UTRs of the REV1 and FANCF mRNAs.

miR-30c enhances chemosensitivity to ADR in BrCa cells in vitro and in vivo

As miR-30c downregulates FANCF and REV1, we wondered if this miRNA could sensitize cells to ADR. We found that endogenous miR-30c was highly expressed in ADR-sensitive p53wt BrCa cells (Fig. 3a). Moreover, ADR significantly increased the levels of miR-30c in p53 wt cells but not in p53-mutated cells (Fig. 3b), suggesting a positive correlation between the miR-30c expression level and sensitivity to ADR in BrCa cells. Furthermore, overexpression of miR-30c significantly increased chemosensitivity to ADR in both MDA-MB-231 and T-47D cells (Fig. 3c). Conversely, miR-30c inhibition significantly decreased chemosensitivity to ADR in both MCF-7 and ZR-75-1 cells (Supplementary Fig. S4). To determine the functional significance of FANCF and REV1 suppression in miR-30c-mediated chemotherapeutic resistance, we transfected MDA-MB-231 and T-47D cells with miR-30c alone or in combination with a FANCF and REV1 


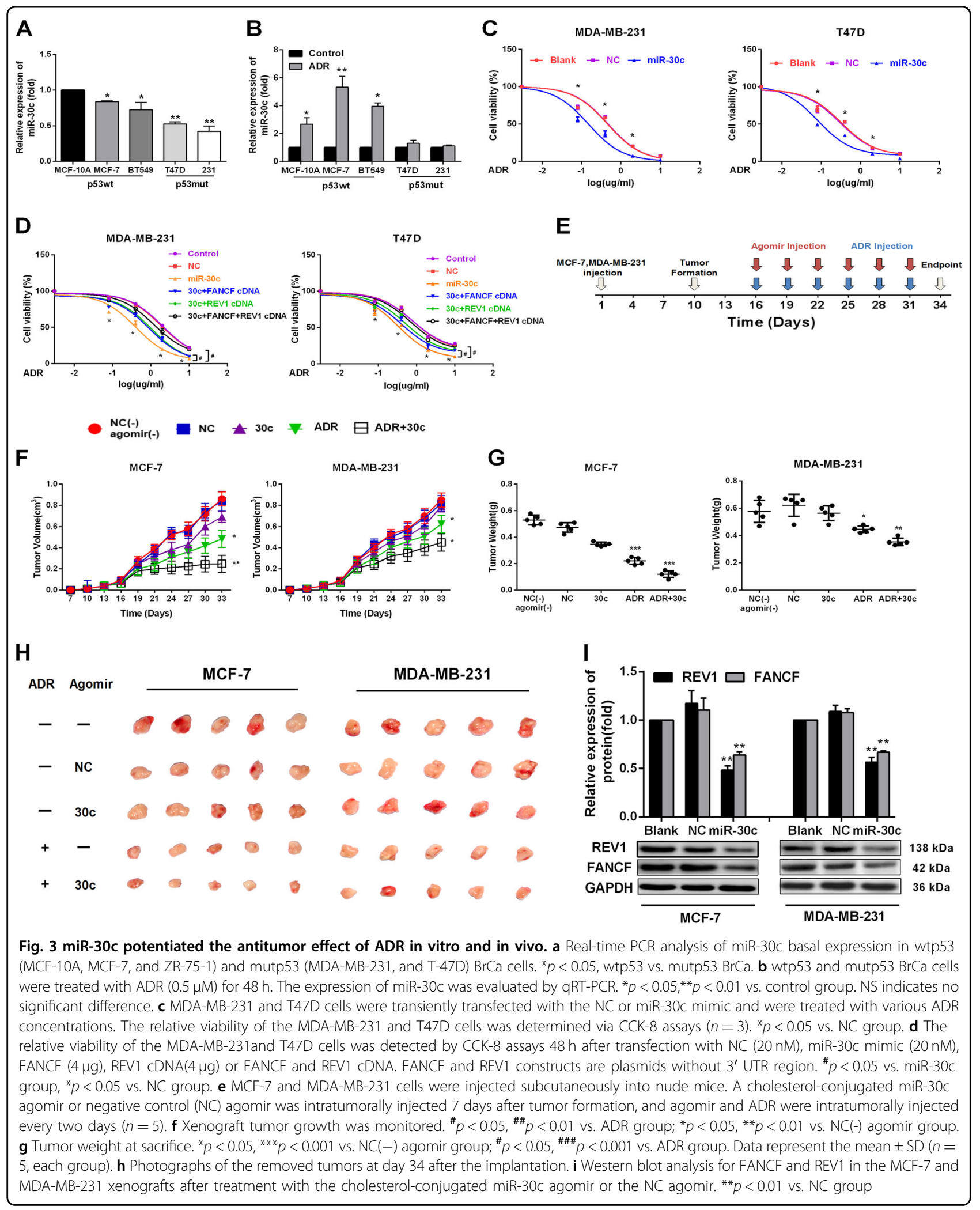


construct without 3' UTR region. The reduced cell survival caused by miR-30c overexpression in ADR-treated MDA-MB-231 and T-47D cells was significantly attenuated by the co-transfection of FANCF and REV1cDNA without 3' UTR region (Fig. 3d). To further validate the importance of FANCF/REV1 in ADR resistance mutp53 cells, we performed the experiment of the effect of the FANCF/REV1 on ADR resistance without overexpressing miR30c in MDA-MB-231 cell and MCF-7 cell. Compared with the control group, ADR sensitivity increased significantly after silencing FANCF and REV1 in MDAMB-231 cell (shown in Supplementary Fig. S5) and decreased significantly after FANCF and REV1 overexpression in MCF-7 cell (Supplementary Fig. S6). And the increased cell survival caused by p53R280K overexpression in ADR-treated MCF-7 cells was significantly attenuated by the co-transfection of FANCF and REV1 siRNA(Supplementary Fig. S7). These results suggested that FANCF + REV1 could be used to target ADR-resistant mutp53 cells and miR-30c enhances the drug sensitivity of $\mathrm{BrCa}$ cells to ADR by regulating the expression of REV1 and FANCF.

To validate the potential pathophysiological significance of miR-30c induction in the therapeutic response of $\mathrm{BrCa}$ to ADR, we next examined the effect of miR-30c on FANCF and REV1 expression and chemosensitivity in nude mice bearing human MCF-7 and MDA-MB-231 xenografts, using cholesterol-conjugated miR-30c mimics (miR-30c agomir) or ADR (Fig. 3e). ADR significantly delayed the growth of MCF-7 and MDA-MB-231 xenograft tumors (Fig. 3f-h). Moreover, miR-30c treatment in combination with ADR significantly reduced the tumor volume and tumor weight at sacrifice compared with those from mice treated with ADR alone, suggesting that miR-30c had a chemosensitizing effect (Fig. 3f-h). Furthermore, the expression of FANCF and REV1 was significantly reduced in miR-30c-overexpressing tumors (Fig. 3i and Supplementary Fig. S8). Taken together, these findings demonstrated that miR-30c enhances the therapeutic activity of ADR in drug-resistant and drugsensitive cells by targeting FANCF and REV1.

\section{miR-30c disturbs the DNA damage response in breast cancer cells}

FANCF and REV1 are two key factors in DNA damage repair pathways ${ }^{12,13}$. In the Cancer Genome Atlas (TCGA) dataset, BrCa patients with higher levels of miR30c have more DNA mutations than cancer patients with lower miR-30c expression (Fig. 4a), indicating that miR$30 \mathrm{c}$ increases genomic instability. Therefore, we examined the effect of miR-30c on DNA damage repair through chromosome fracture analysis and alkaline COMET assays. miR-30c overexpression increased the number of chromosomal breakages as well as comet tail length in the presence and absence of ADR in MCF-7 and MDA-MB231 cells (Fig. 4b, c).

DSBs can induce the phosphorylation of H2AX, forming $\gamma$-H2AX, $\gamma-\mathrm{H} 2 \mathrm{AX}$ foci represent the number of DSBs $^{14,15}$. The number of $\gamma$-H2AX foci induced by ADR treatment were significantly increased in miR-30coverexpressing cells (Fig. 4d), suggesting that miR-30c delays DNA damage repair.

\section{p53 regulates REV1 and FANCF through the activation of miR-30c transcription by binding to the promoter region of $\mathrm{miR}-30 \mathrm{c}$}

We further searched online databases (http://www. biobase-international.com/ Gene-regulation) to identify transcription factors that regulate miR-30c transcription. We found p53 binds to the promoter region of miR-30c, with its binding site is located within intron 5 of NFYC (the miR-30c host gene) on GRCh38.p2 of chromosome 1 (Fig. 5a). Luciferase activity assays showed that the overexpression of wtp53, but not mutated p53, significantly increased the luciferase activity. Moreover, in comparison with the transfection of wtp53 (p53cDNA), luciferase activity induction was diminished in cells transfected with mutp53 (p53R280K) (Fig. 5b). Furthermore, ADR, a genotoxic agent that activates $\mathrm{p} 53$, increased luciferase activity, and pifithrin- $\alpha$, a specific p53 inhibitor, inhibited the p53-induced increased luciferase activity. However, pifithrin- $\alpha$ and ADR treatment significantly increased the luciferase activity after pifithrin- $\alpha$ treatment alone in HEK-293T and MCF-7 cells (Fig. 5b and Supplementary Fig. S9). ChIP assays confirmed that p53 directly binds to the identified binding site of the miR-30c promoter in vivo (Fig. 5c). Further, we found that ADR, which significantly induced the expression of p53, significantly increased the levels of miR-30c and pri-miR-30c in MCF7 but not in MDA-MB-231 cell (Fig. 5d). Similarly, the specific p53 agonist nutlin-3 also increased the expression of miR-30c and pri-miR-30c in MCF-7 but not in MDAMB-231 cell (Supplementary Fig. S10a). The overexpression of wtp53 increased miR-30c expression in both MCF-7 and MDA-MB-231 cells (Supplementary Fig. S10b). Furthermore, p53 shRNA significantly reduced the expression of miR-30c in the presence or absence of ADR. (Fig. 5e).

Our results indicated that miR-30c is regulated at the transcriptional level. As positive and negative controls, we tested two p53 targets with or without treating the cells with the translation inhibitor cycloheximide. The direct transcriptional target gene p21CIP1/WAF1 was upregulated after the induction of wtp53 irrespective of functional translation(Supplementary Fig. S11a). As an example of a gene indirectly controlled by p 53 , cyclin B2 mRNA was downregulated, but it did not change significantly when translation was inhibited (Supplementary 

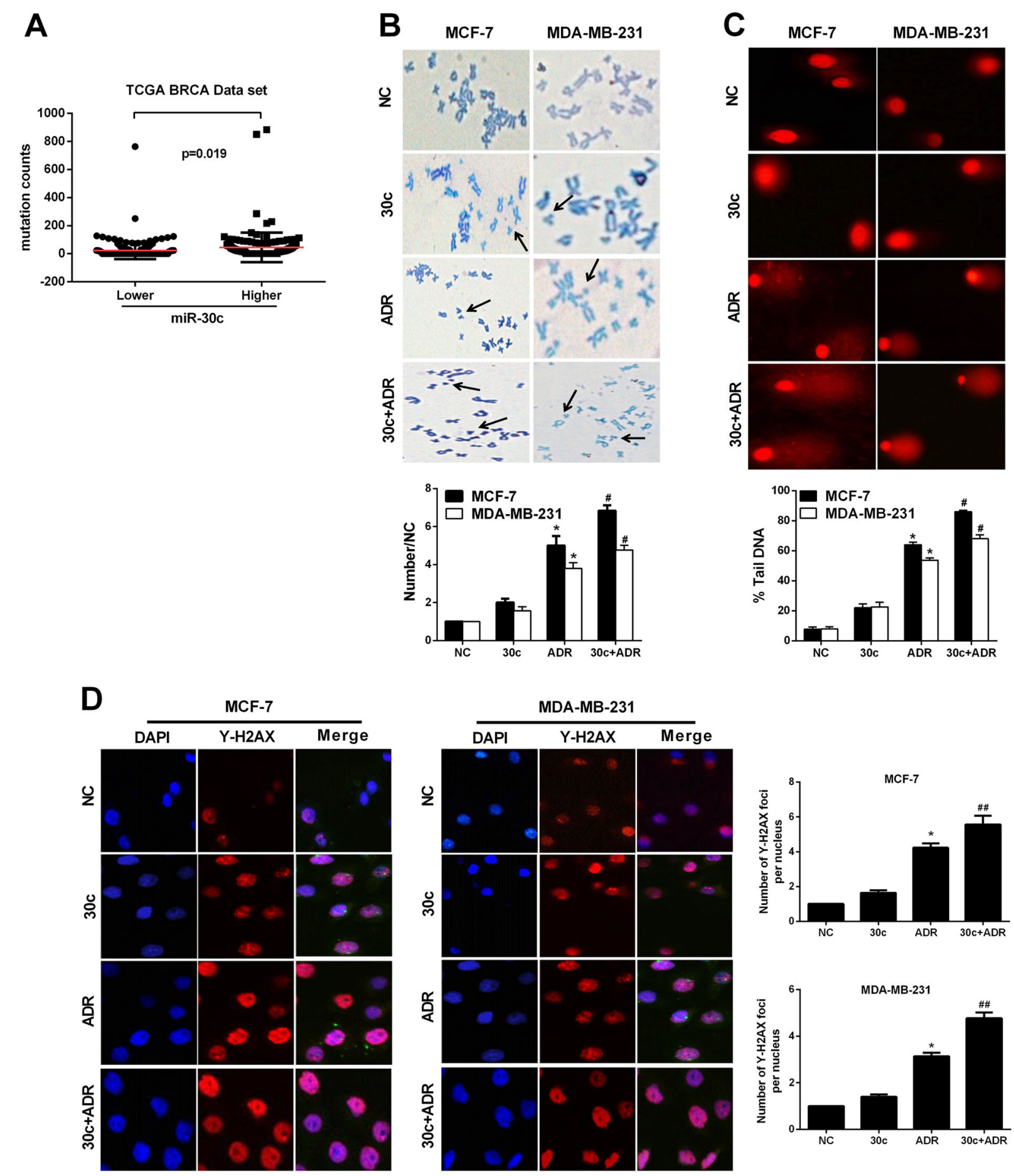

Fig. 4 miR-30c enhanced DNA damage and genome instability following ADR treatment. a Genomic instability (mutation counts) was detected in TCGA BrCa patients ( $p<0.05, n=352)$. b, c MCF-7 and MDA-MB-231 cells were transfected with a negative control (NC) mimic (20 nM), miR-30c mimic (20 nM), ADR (0.5 $\mathrm{MM})$ or miR-30c + ADR for $48 \mathrm{~h}$. Chromosomes were then subjected to cytogenetic analysis. A total of 50 cells from each sample was examined and scored. Arrowheads indicate chromosome breaks. Magnification, $\times 400$. For each sample, 50 comet tails were analyzed. ${ }^{*} p<0.05$ vs. NC group, ${ }^{\#} p<0.05$ vs. ADR group. $\mathbf{d}$ Representative immunofluorescent images of $y-H 2 A X$ staining in MCF-7 and MDA-MB231 cells treated with a negative control $(\mathrm{NC})$ mimic $(20 \mathrm{nM})$, miR-30c $(20 \mathrm{nM})$, ADR $(0.5 \mu \mathrm{M})$, or miR-30c + ADR for 48 h. Nuclei were counterstained with DAPI. For each group, 50 nuclei were analyzed. Magnification, $\times 200$. Quantification results are shown on the right. ${ }^{*} p<0.05$ vs. NC group, ${ }^{\# \#} p<$ 0.01 vs. ADR group. Data represent the mean $\pm S D(n=3$, each group) 


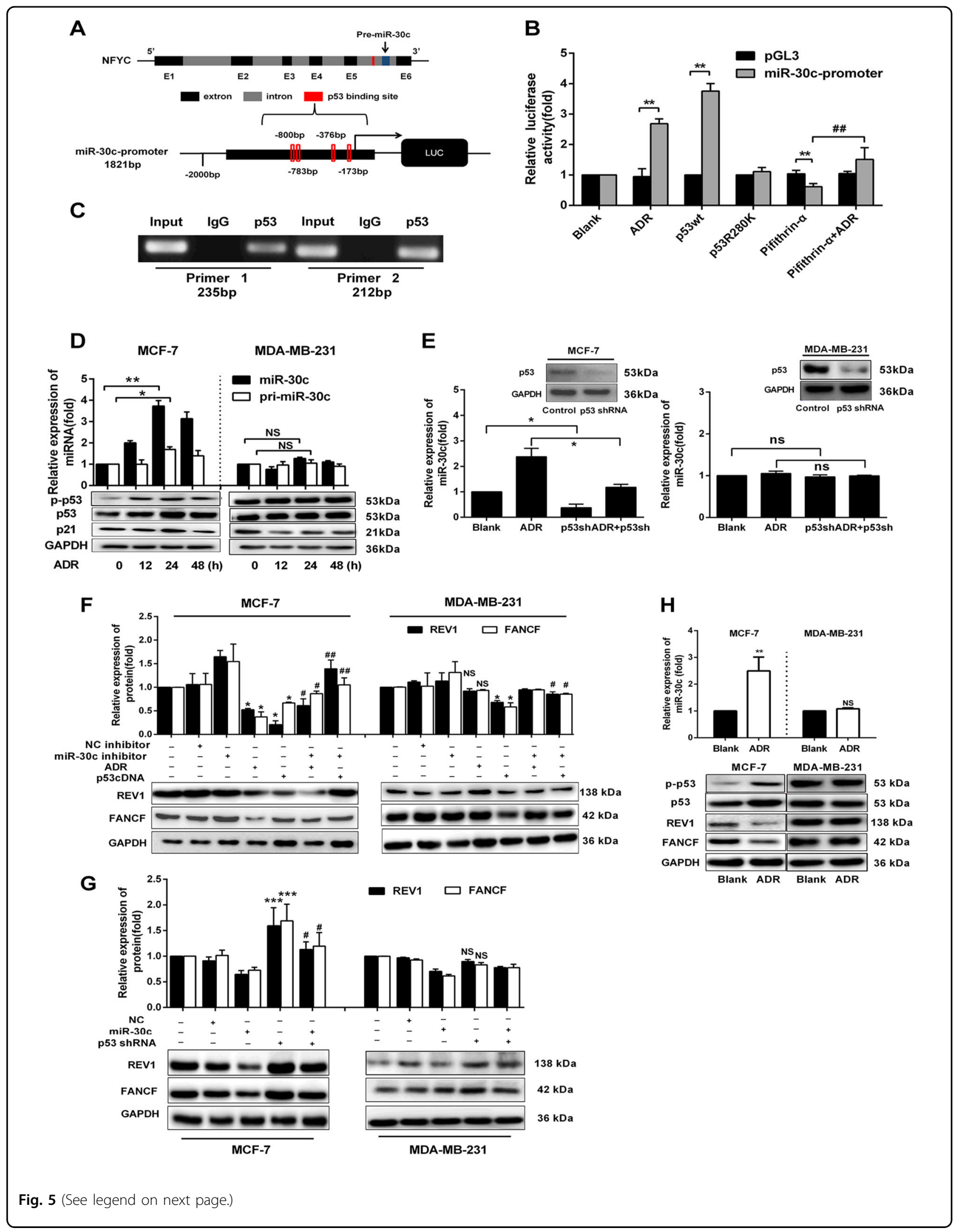


(see figure on previous page)

Fig. 5 p53 regulates the expression of FANCF and REV1 via miR-30c in BrCa. a Schematic representation of NFYC (miR-30c host gene) and putative p53 binding sites in intron 5 of NFYC. $\mathbf{b}$ HEK-293T cells were treated with pcDNA3.1-p53 (wtp53), pcDNA3.1-p53R280K (mutp53), ADR $(0.5 \mu \mathrm{M})$, pifithrin- $a(10 \mu \mathrm{M})$, pifithrin- $a+$ ADR or the miR-30c promoter constructs (in the pGL3 vector). Relative luciferase activity was assayed. ${ }^{* *} p<$ 0.01 vs. PGL3 vector, ${ }^{\# \#} p<0.01$ vs. pifithrin-a group. c ChIP assay showing endogenous p53 bound to the miR-30c promoter in the p53 binding site region in MCF-7 cells. $\mathbf{d}$ MCF-7 and MDA-MB-231 cells were treated with ADR $(0.5 \mu \mathrm{M})$ for 12, 24, and $48 \mathrm{~h}$. The expression of mature miR-30c and primiR-30c was evaluated by qRT-PCR. The protein expression of p-p53, p53, and p21 was examined by Western blotting. ${ }^{*} p<0.05$, ${ }^{* *} p<0.01$ vs. $0 \mathrm{~h}$ group. e MCF-7 and MDA-MB-231 cells were treated with control, p53shRNA, ADR, or p53shRNA + ADR for 48 h. qRT-PCR showed that the miR-30c expression changes. The protein expression of p53 was examined by Western blotting. f MCF-7 and MDA-MB-231 cells were transfected with NC inhibitor $(20 \mathrm{nM})$ or miR-30c inhibitor $(20 \mathrm{nM})$ and were then treated with ADR and p53cDNA. The expression of FANCF and REV1 was analyzed by Western blotting. MCF-7 cells: ${ }^{*} p<0.05,{ }^{* *} p<0.01$ vs. Blank group; ${ }^{\#} p<0.05$ vs. ADR group, ${ }^{\# \#} p<0.01$, vs. p53cDNA group. MDA-MD-231 cells: ${ }^{*} p<$ 0.05 vs. Blank group; $" p<0.05$ vs. p53cDNA group. g FANCF and REV1 expression in MCF-7 and MDA-MB-231 cells transfected with p53 shRNA, miR$30 \mathrm{c}$ mimic (miR-30c) or the negative control (NC). The expression of FANCF and REV1 was analyzed by Western blotting. ${ }^{* *} p<0.01$, ${ }^{* * *} p<0.001 \mathrm{vs}$. Blank group; ${ }^{*} p<0.05$ vs. Blank group. $\mathbf{h}$ qRT-PCR analysis of miR-30c expression in ADR-treated MCF-7 and MDA-MB-231 xenografts. Western blot analysis of p-p53, p53, FANCF, and REV1 expression in ADR-treated MCF-7 and MDA-MB-231 xenografts. ${ }^{* *} p<0.01,{ }^{* * *} p<0.001$ vs. Blank group. NS indicates no significant difference. Data represent the mean $\pm \mathrm{SD}(n=3$, each group)

Fig. S11b). Interestingly, the levels of miR-30c were induced after p53 expression independent of functional translation (Supplementary Fig. S11c), which supports the notion that the miR-30c gene locus is a direct target of $\mathrm{p} 53$.

We further examined whether p53 regulates REV1 and FANCF via miR-30c in BrCa cells. We found that wtp53 overexpression significantly suppressed the expression of FANCF and REV1 in MCF-7 and MDA-MB-231 cells. p53 activation induced by ADR suppressed the expression of FANCF and REV1 in MCF-7 but not in MDA-MB-231 cell (Fig. 5f). miR-30c inhibitors inhibited the effects of wtp53 overexpression and ADR on the expression of FANCF and REV1 (Fig. 5f). In addition, p53 knockdown by shRNA significantly increased the expression of REV1 and FANCF in MCF-7 cell, and this effect was blocked by miR-30c mimics (Fig. 5g). In line with these in vitro results, we also observed that ADR treatment significantly increased the miR-30c levels and decreased the expression of FANCF and REV1 in MCF-7 but not in MDA-MB-231 xenograft tumors (Fig. 5h, Supplementary Fig. S12). Therefore, our data suggest that REV1 and FANCF are regulated by wtp53 through miR-30c.

\section{Reduced miR-30c expression is highly correlated with human BrCa p53 mutational status and is associated with poor survival}

The above results predict that tumors with mutated p53 should have low expression of miR-30c and high expression of FANCF and REV1. To investigate any potential association among miR-30c expression, p53 mutation status, and clinical $\mathrm{BrCa}$ data, we examined a BrCa RNAseq dataset from TCGA. We observed a significant difference in miR-30c expression between tumors $(n=1109)$ and normal tissues $(n=113)$ (Fig. 6a). Kaplan-Meier survival analysis showed a highly significant difference in overall survival between the high expression $(n=631)$ and low expression $(n=631)$ groups. Elevated miR-30c expression significantly correlated with a longer survival time in $\mathrm{BrCa}$ patients $(p<$ 0.001 , Fig. 6b). We then compared miR-30c expression in mutp53 vs wtp53 tumors in patients with $\mathrm{BrCa}$ using the TCGA BrCa database. Tumors with mutated p53 had lower miR-30c expression than those with wtp53 $(p<$ 0.001 , Fig. 6c). To further examine the effect of p53 mutations on miR-30c levels and FANCF and REV1 protein levels in specimens from individuals with $\mathrm{BrCa}$, we analyzed miR-30c, FANCF and REV1 in our cohort for which 118 primary breast tumor samples were available. The presence of potential p53 gain-of-function mutations was inferred by strong p53 staining via IHC (Fig. 6d). Consistent with the TCGA miRNA-seq dataset analysis, miR-30c expression was markedly higher in tumor tissues with wtp53 (Fig. 6e). IHC analysis showed that p53mutated tumors exhibited high staining for FANCF and REV1. In contrast, tumors with wtp53 exhibited low staining for the FANCF and REV1 proteins (Fig. 6e). Spearman correlation analysis showed that FANCF and REV1 protein expression was negatively correlated with miR-30c expression in $\mathrm{BrCa}$ tissues (Fig. 6f). These observations support the notion that p53 activates miR30c to inhibit REV1 and FANCF expression. miR-30c has prognostic value and may play an important role in cancer progression.

\section{Discussion}

Chemotherapeutic resistance, particularly to ADR, represents a major impediment to successfully treating $\mathrm{BrCa}$. Currently, no predictive biomarkers for ADR resistance have been identified for general clinical use. As the most frequently mutated gene in human tumors ${ }^{3}$, p53 mutations contribute to resistance to a variety of standard chemotherapies $^{16-18}$. While p53 mutational status has been linked to a lack of sensitivity to anthracyclines ${ }^{19,20}$, its correlation with resistance to ADR-based chemotherapeutics has not always been straightforward ${ }^{21-24}$, with 


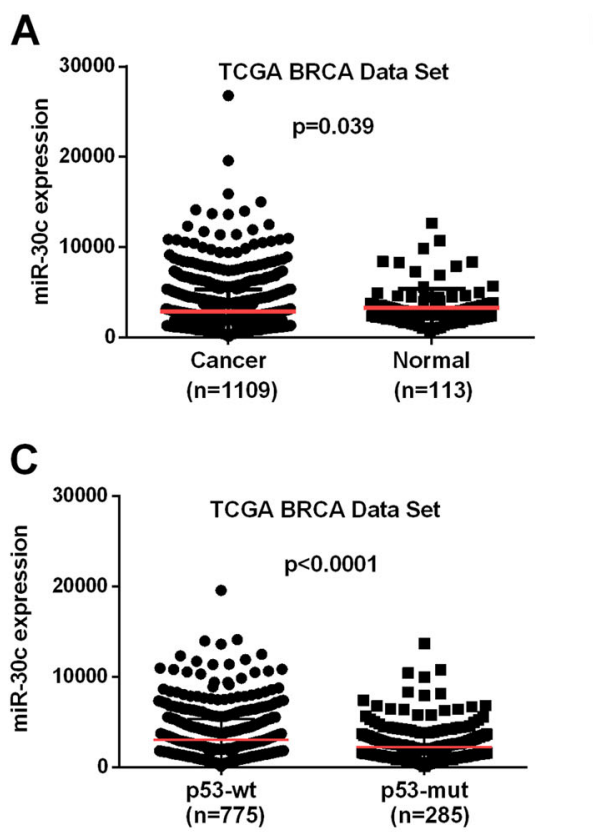

B
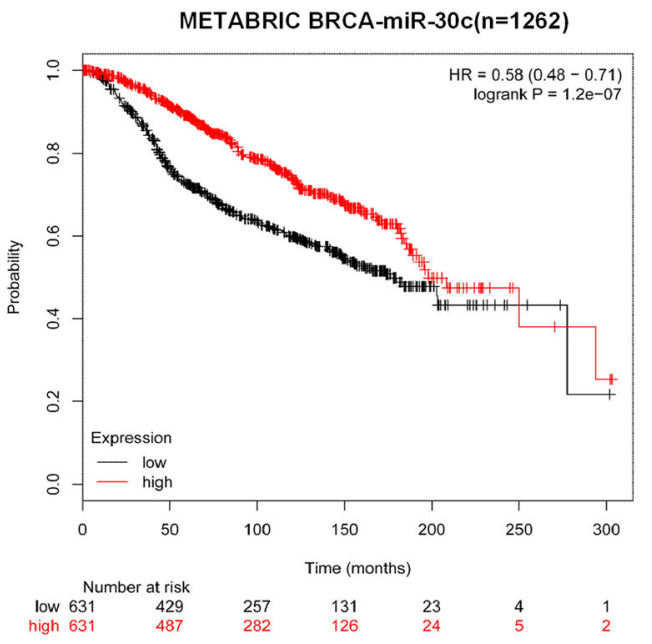

D
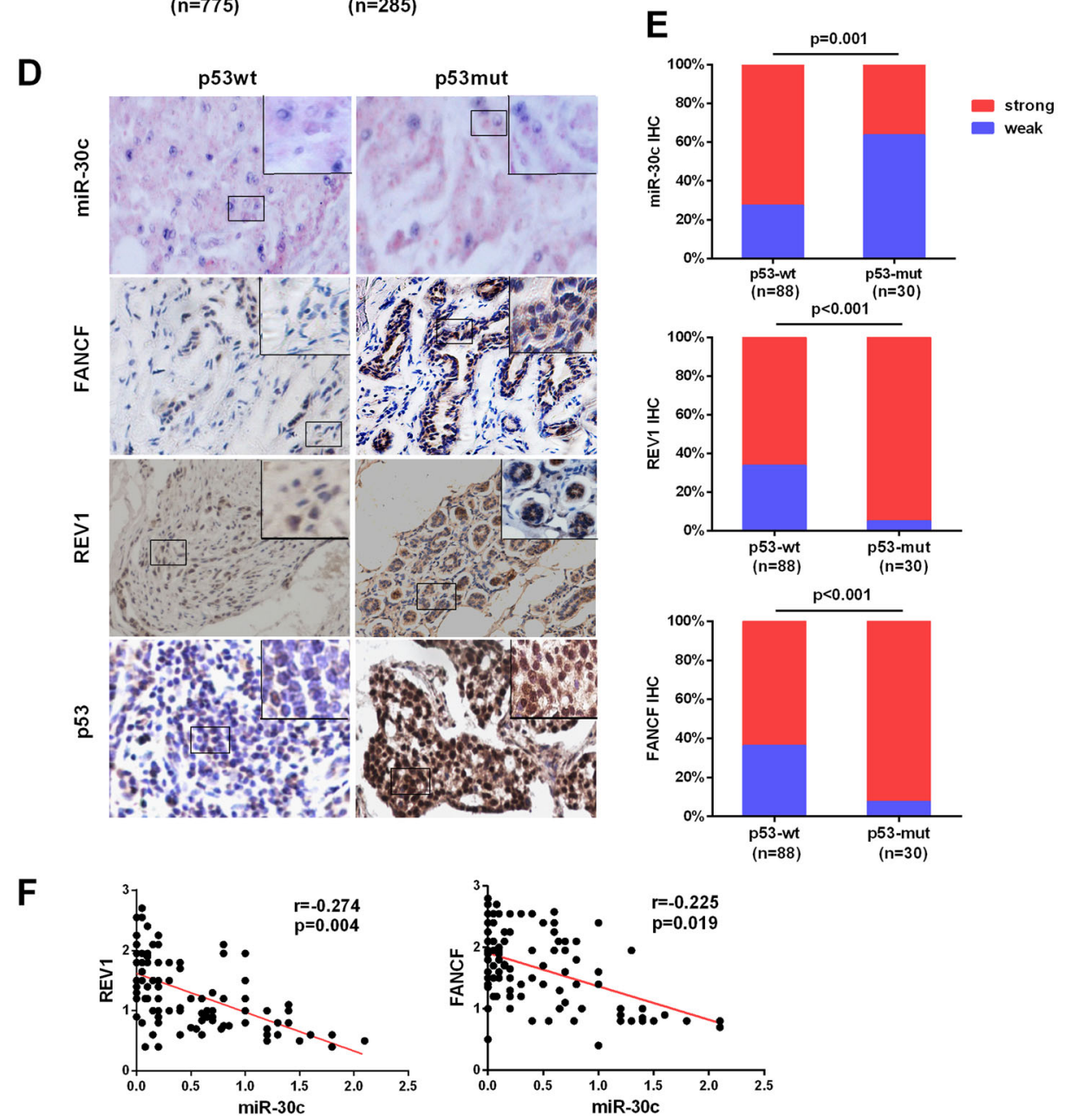

Fig. 6 (See legend on next page.) 
(see figure on previous page)

Fig. 6 Expression of miR-30c, FANCF and REV1 proteins is elevated in mutp53 specimens from patients with BrCa. a miR-30c expression in normal breast tissues $(n=113)$ and BrCa tissues $(n=1109)$ in The Cancer Genome Atlas (TCGA) dataset. The $p$ value was calculated via a nonparametric Mann-Whitney test. b Kaplan-Meier overall survival curves according to miR-30c expression in METABRIC BrCa patient cohorts. c A whisker plot showing miR-30c expression in patients with mutp53 tumors $(n=285)$ and wtp53 tumors $(n=775)$ using TCGA database. d Representative images of miR-30c in situ hybridization and FANCF and REV1 IHC for 118 cases of BrCa expressing wtp53 and mutp53. Magnification, $\times 200$. Small frames indicate the magnified regions. e Quantitative data for miR-30c, FANCF and REV1 protein staining in $\mathbf{d}$. Statistical significance was determined by Wilcoxon rank-sum tests. $\mathbf{f}$ Correlation analysis of miR-30c and REV1 or FANCF protein expression in BrCa patients

studies showing variable responses. It is possibly due to molecular changes, especially to molecules up- or downstream of mutp53 networks. Furthermore, although drugs targeting mutp53 have been developed ${ }^{17}$, their efficacy in the treatment of human cancer is unclear. Therefore, exploring the molecules involved in mutp53 networks may facilitate the prediction of chemotherapy response as well as the development of individualized chemotherapy for tumors with p53 mutations in the future. In this regard, our study highlights a mechanism of intrinsic ADR resistance in p53-mutated $\mathrm{BrCa}$ involving miR-30c/ FANCF/REV1-mediated DNA damage response.

To date, different molecular mechanisms of action underlying mutant p53 gain-of-function have been described $^{25}$. DNA repair mechanisms are considered a vital target for improving cancer therapy and reducing resistance to many DNA-damaging agents currently in use as standard-of-care treatments. In our study, we focused on the role of DNA repair in ADR resistance in p53-mutated BrCa. We found that FANCF and REV1, which are two important DNA repair genes, are increased the most in p53-mutatated $\mathrm{BrCa}$ cell lines compared to wtp53 cell lines. The FA/BRCA pathway is involved in the maintenance of cell growth, proliferation, and apopto$\operatorname{sis}^{26,27}$. FANCF is critically involved in regulating the function of the FA/BRCA pathway by maintaining the stability of the FA core complex as well as the ubiquitin activation (monoubiquitination) of the FANCD2 pro$\operatorname{tein}^{28}$. Our previous studies found that the inhibition of FANCF blocked the functions of FA/BRCA pathway and enhanced antitumor drug sensitivity in cancer cells ${ }^{29-32}$. REV1-mediated TLS may play a critical role in the development of acquired chemoresistance ${ }^{33}$ and improving chemotherapeutics ${ }^{34}$. Therefore, the simultaneous inhibition of FANCF and REV1 is a theoretically valid strategy for sensitizing tumor cells to DNA-damaging agents and preventing the development of chemoresistance; however, one concern is that this combination may also lead to toxicity in some normal tissues.

miR-30c as a tumor suppressor, the current studies demonstrate that miR-30c plays a role in chemoresistance by regulating the anti-apoptotic gene $\mathrm{YWHAZ}^{35}$ and epithelial-mesenchymal transition (EMT) related genes $\mathrm{TWF}^{36}$. In addition to its role in regulating chemoresistance, miR-30c also regulates embryo development through downregulation of several tested DNA damage response (DDR) genes ${ }^{37}$. Here, we revealed a new role for miR-30c as a tumor suppressor: ${ }^{38-40}$ miR-30c may provide a way for cells to shut down DNA repair machinery after extensive damage. Moreover, the increased miR-30c level without ADR did not affect cancer cell growth (Supplementary Fig. S13), which is consistent with the results reported by Bockhorn $\mathrm{J}^{36}$. Thus, miR-30c, which downregulates both FANCF and REV1, is a potentially powerful therapeutic agent for improving the efficacy of ADR. However, miR-30c intervention alone is insufficient to reverse ADR resistance and other signaling pathways may also play a significant role in ADR resistance in p53mutant cells. Our findings provided a clue to the ADR resistance of p53 mutations and outline a novel pathway for interrupting DNA damage repair to enhance the anticancer function of ADR.

More importantly, our work reveals that miR-30c is a target of p53 and that p53 regulates miR-30c transcriptional activation. A previously published analysis revealed that a cohort of miRNAs exhibit p53-dependent upregulation following DNA damage and defined miR-30c as one of the potential targets of $\mathrm{p} 53^{41}$. Since the $\mathrm{p} 53$ conserved sequence matches to the miR-30c promoter region, this binding also presents in other tumors (Supplementary Fig. S14). Most p53 mutations found in cancers are located in a domain that is required for both its miRNA processing function and transcriptional activity ${ }^{42,43}$. As expected, mutation of p53 abolished this response. Thus, our data suggest that p53 mutation-conferred resistance to ADR might be related to the decreased miR-30c levels and increased FANCF and REV1 protein levels in BrCa cells.

It is well known that oncogenic activities acquired by mutant p53 include increased proliferation and acquisition of resistance to specific therapies ${ }^{44}$. REV1/FANCF as a DNA damage response gene has previously been shown to be induced by DNA damage. Unexpected, we found that Rev1 and FANCF are decreased upon ADR treatment in MCF-7 cell.These findings seemed to suggest that REV1 and FANCF failed to really repair the ADR-induced DNA damage in our study. We detected the expression of REV1 and FANCF at ADR different concentrations and different treatment times in MCF-7 cell. As shown in Supplementary Fig. S15\& S16, when the ADR concentration is small or the treatment time is short, the 
DNA damage repair pathway is activated, the cells intend to repair the DNA and survive. When the concentration of ADR is large or the treatment time is longer, the expression of REV1 and FANCF is decreased in breast cancer cells. Therefore, this may be the reason why our results are inconsistent with others.

In conclusion, our work suggests a role for miR-30c in the regulation of DNA repair through the modulation of FANCF and REV1 expression. Our findings highlight the functions and roles of miRNAs in $\mathrm{BrCa}$ and suggest that resistance to ADR in p53-mutant $\mathrm{BrCa}$ may be related to miR-30c/FANCF/REV1-mediated DNA damage response.

\section{Materials and methods Cell culture}

The BrCa cell lines MCF-7, ZR-75-1, T-47D, MDAMB-231 (ATCC, USA) and MCF-10A (ATCC, USA) were cultured under standard conditions, as recommended by their manufacturers. pMKO.1 puro p53 shRNA (Plasmid \#10671) and pCMV-Neo-Bam p53wt (Plasmid \#16434) were obtained from Addgene (http://www.addgene.org). p53R280K cDNA, REV1 cDNA and FANCF cDNA plasmids without 3' UTR region were obtained from GeneChem (www.genechem.com.cn).

\section{Tissue samples}

Formalin-fixed and paraffin-embedded $\mathrm{BrCa}$ samples were obtained from the Department of Surgical Oncology at the First Affiliated Hospital of China Medical University. None of the patients had received radiotherapy or chemotherapy before surgery. The use of human tissues was approved by the ethics committee of China Medical University.

\section{miRNA and RNA interference}

miR-30c mimic (miR-30c), miR-30c negative control (miR-NC), miR-30c inhibitor (Inh-30c), miR-30c inhibitor negative control (Inh-NC) and negative control siRNAs (siRNA duplexes with non-specific sequences) were synthesized and purified by Riobio (Riobio, Co., Guangzhou, China). Cells were transfected with miR-30c (20 nM), Inh30c $(20 \mathrm{nM})$, REV1 siRNA $(20 \mathrm{nM})$ or FANCF siRNA $(20 \mathrm{nM})$ using Lipofectamine 2000. The expression levels of miR-30c and other mRNAs were quantified $48 \mathrm{~h}$ after transfection. REV1 siRNA and FANCF siRNA were obtained from Riobio.

\section{Cell proliferation assay}

Cells were transfected with p53R280K(4ug), p53cDNA (4ug), miR-30c mimics (20 nM), miR-30cinhibitor (20 nM), FANCFcDNA/REV1cDNA(4ug), or FANCFsiRNA / REV1siRNA (20 nM) for $24 \mathrm{~h}$. Cells were then seeded onto 96-well plates at a density of $4 \times 10^{3}$ cells/ well. After culture for $24 \mathrm{~h}$, cells were treated with serial dilutions of ADR, followed by treatment with CCK-8 (Dojindo Molecular Technologies Inc., Japan) for $1 \mathrm{~h}$. The absorbance at $450 \mathrm{~nm}$ was measured using a multi-mode reader (LD942, Beijing, China).

\section{Immunoblot and reporter assays}

The immunoblot and reporter assays were performed as described previously ${ }^{45}$. The antibodies used are described in Supplementary Table S2. Bands were visualized with a chemiluminescent detecting system (Amersham, Freiburg, Germany). The intensity of the western blot bands was analyzed by ImageJ software (http://rsb.info.nih.gov/ij).

The human REV1-3'-UTR (766 bp) and FANCF-3'UTR (2362 bp) was amplified by PCR and cloned into the Xbal site of the pGL3 vector (Promega). Mutations in the miRNA-binding site were generated using PCR-based mutagenesis (Takara, Dalian, China). To generate miR30c promoter plasmids, the miR-30c promoter regions $(-1832$ to $+150 \mathrm{bp})$ were amplified by PCR and cloned to the pGL3-Basic vector (Promega, WI, USA), respectively. The primers used are listed in Supplementary Table S1.

To study the effect of miR-30c on FANCF and REV1 expression via targeting the 3'-UTRs of FANCF and REV1, Luciferase reporter vectors (control) or vectors containing wild-type (pGL3-REV1-3'UTR-Full, pGL3FANCF-3'UTR-Full) or mutated 3'-UTRs (pGL3-REV13'UTR-Mut, pGL3-FANCF-3'UTR-Mut) of REV1 and FANCF mRNAs were cotransfected into $293 \mathrm{~T}$ cells with miR-30c, using Lipofectamine 2000. To study the direct binding of p53 to the promoter region of miR-30c, the miR-30c-promoter reporter constructs were cotransfected with p53cDNAwt, or p53cDNA-R280K into HEK-293T/ MCF-7/HCT-116/OVCAR3 cells using Lipofectamine 2000. After transfection for $48 \mathrm{~h}$, luciferase activity was detected using the Dual Luciferase Reporter Gene Assay kit (Promega). Relative luciferase activity normalized to the control.

\section{Quantitative real-time PCR}

Total RNA extraction from cells and quantitative realtime PCR were performed as described previously ${ }^{45}$. Total RNA was isolated from tumor cells using TRIZOl reagents (Invitrogen, CA, USA) according to the manufacture's protocol. qRT-PCR were performed using SYBR Premix ExTaq ${ }^{\text {ma }}$ II kit (Takara). The primers are listed in Supplementary Table S2. Relative expression of miR-30c was normalized to U6 expression and REV1 and FANCF was to GAPDH. The fold change for each RNA relative to the control was calculated using the $2^{-\triangle \triangle \mathrm{Ct}}$ method.

\section{Immunohistochemistry}

For immunohistochemistry, slides were deparaffinized and rehydrated. Antigen retrieval was performed by a pressure cooker for $10 \mathrm{~min}$ in $0.01 \mathrm{M}$ citrate buffer $(\mathrm{pH}$ 
6.0), followed by treatment with $3 \%$ hydrogen peroxide for $5 \mathrm{~min}$. Next, slides were blocked in sheep serum for $30 \mathrm{~min}$, and then incubated with antibodies specific for REV1 (Rabbit Polyclonal 1:50 dilution, novus) and FANCF (Rabbit Polyclonal 1:200 dilution, Bioss) overnight at $4{ }^{\circ} \mathrm{C}$. Immunostaining was performed using DAB according to the manufacturer's instructions. The slides were mounted and the images were captured and analyzed by a fluorescence microscope.

\section{MiR-30c in situ hybridization}

Paraffin sections were mounted on Super frost + glass slides and deparaffinized. The slides were then treated with proteinase- $\mathrm{K} 10 \mu \mathrm{g} / \mathrm{ml}$ at $37^{\circ} \mathrm{C}$ for $10 \mathrm{~min}$, prehybridizd in Exiqon hybridization buffer (Exiqon, Vedbæk, Denmark) at $37^{\circ} \mathrm{C}$ for $2 \mathrm{~h}$, hybridized with $50 \mathrm{nM}$ miRNA-30c probe and washed stringently with $5 \times$ SSC, $1 \times \mathrm{SSC}$ and $0.2 \times \mathrm{SSC}$ buffers at $37^{\circ} \mathrm{C}$ for $30 \mathrm{~min}$. DIG blocking reagent (Roche, Mannheim, Germany) was added for $1 \mathrm{~h}$ at $37^{\circ} \mathrm{C}$ in maleic acid buffer with $2 \%$ sheep serum. After which, alkaline phosphatase-conjugated anti-digoxigenin was added at $4{ }^{\circ} \mathrm{C}$ for $12 \mathrm{~h}(1: 500$ in Roche blocking reagent). 4-nitroblue tetrazolium (NBT) and 5-brom-4-chloro-3'-Indolylphosphate (BCIP) substrate (Roche) were used for enzymatic development to form dark-blue NBT-formazan precipitates at $37^{\circ} \mathrm{C}$ for $60 \mathrm{~min}$. The sections were lightly counterstained with nuclear fast red (Vector Laboratories, Burlingname, CA) at $25^{\circ} \mathrm{C}$ for $1 \mathrm{~min}$ and mounted. The expression of miR30c was detected, using digoxin-labelled locked nucleic acid-modified RNA probes against the full length mature miR-30c sequence. MiR-30c probe sequences are listed in Table S1.

\section{Chromosomal breakage analysis}

Cells were transfected with the miR-30c mimic $(20 \mathrm{nM})$ and treated with ADR $(0.5 \mu \mathrm{M})$ for $48 \mathrm{~h}$. Subsequently, colcemid was added at a final concentration of $100 \mathrm{ng} / \mathrm{ml}$ and incubated for $90 \mathrm{~min}$, after which the cells were treated with a hypotonic solution $(0.075 \mathrm{M} \mathrm{KCL})$ for $30 \mathrm{~min}$. The cells were fixed with 3:1 methanol/acetic acid and stained with Giemsa stain, and 50 metaphase spreads per group were used to evaluate chromosomal breakage.

\section{Single-cell alkaline electrophoretic (comet) assays}

DNA damage was assessed via a single-cell gel electrophoresis assay under alkaline conditions using a Comet Assay kit according to the manufacturer's protocol (Trevigen, Gaithersburg, MD, USA, 4250-050-K). Briefly, cells were harvested $48 \mathrm{~h}$ after miR-30c mimic transfection and ADR treatment. Each cell sample was mixed with low melting point agarose and plated on a CometSlide. Subsequently, the cells were lysed overnight at $4{ }^{\circ} \mathrm{C}$, subjected to electrophoresis at $25 \mathrm{~V}$ and $300 \mathrm{~mA}$ for $20 \mathrm{~min}$ under alkaline conditions, and stained with EB staining solution. Fifty cells were randomly chosen to score each sample. The percentage of Tail DNA was determined using Comet IV analysis software (Perceptive Instruments Ltd., Bury St. Edmunds, UK).

\section{Immunofluorescence staining}

Cells treated with ADR were fixed for immunofluorescence staining as previously described ${ }^{46}$. Mouse anti-human $\gamma$-H2AX conjugated to Alexa Fluor 555 goat anti-mouse IgG was used (Supplementary Table S2). 40,6diamidino-2-phenylindole (DAPI) (Sigma) was used to stain the nuclei. Isotype controls were used for all assays. Immunostaining was analyzed using a fluorescence microscope (Nikon, Japan). Approximately 50 cells were scored for the presence of foci per experimental group.

\section{Chromatin immunoprecipitation (ChIP) assay}

ChIP assays were performed using a commercially available kit (Millipore, Merck KGaA, Darmstadt, Germany), according to the manufacturer's instructions. Briefly, cells $\left(2 \times 10^{6}\right)$ were crosslinked in $1 \%$ formaldehyde for $10 \mathrm{~min}$ at room temperature, with the crosslinking stopped by the addition of $0.125 \mathrm{M}$ glycine. A primary antibody against p53 (Cell Signaling Technology, Danvers, MA. USA) was used to capture the chromatin. After overnight capture at $4{ }^{\circ} \mathrm{C}$, the chromatin was collected, purified, and de-crosslinked at $65^{\circ}$ C. The precipitated DNA fragments were quantified by PCR analysis, using the primers listed in Supplementary Table S2.

\section{Animal study}

All animal work was performed in accordance with a protocol approved by the Animal Center and Animal Ethics Committee of China Medical University ${ }^{47}$. To establish breast tumor xenograft model, MCF-7 and MDA-MB-231cells $\left(5 \times 10^{6}\right)$ were suspended in $100 \mu \mathrm{l}$ PBS and inoculated subcutaneously into the flank of $\mathrm{BALB} / \mathrm{c}$ athymic nude mice. All mice were supplemented with estrogen pellets. Tumors were measured every other two days after they were visible to the naked eye. Sixteen days after tumor cell transplantation, cholesterolconjugated miR-30c agmir $(1 \mathrm{nmol})$ in $0.1 \mathrm{ml}$ saline were intratumorally injected into the tumor mass every 3 days for 2 weeks. Adriamycin $(1 \mathrm{mg} / \mathrm{kg})$ was administered intravenously three times a week for 2 weeks. Tumor growth was monitored by caliper measurement twice a week. Tumor volume (V) was determined by the length (L) and width (W) according to the following formula: $\mathrm{V}=\left(L \times W^{2}\right) / 2$. Mice were sacrificed, and tumors were removed and weighed 34 days after tumor transplantation. 


\section{Statistical analysis}

Statistical analysis was performed using SPSS17.0 statistical software (SPSS Inc, Chicago, IL, USA). Data are presented as the mean \pm SD of three independent experiments. Student's $t$-test was used for comparisons. OS analysis was estimated by the Kaplan-Meier method. The Spearman rank test was used to identify the correlations between miR-30c and REV1 or FANCF. A $p$-value of $<0.05$ was considered statistically significant.

\section{Acknowledgements}

The authors thank Prof. Liwang Cui (Department of Entomology, Pennsylvania State University, University Park, PA 16802 USA) for their critical review of the article. This work was supported by grants from National Natural Science Foundation of China (No 81202551, U1608281, 81501346, 81573462) the Key Laboratory Foundation from Shenyang S\&T Projects (F16-094-1-00), Shenyang S\&T Projects (17-123-9-00, Z18-4-020).

\section{Author details}

${ }^{1}$ Department of Pharmacology, School of Pharmacy, China Medical University, No. 77 Puhe Road, Shenyang North New Area, 110122 Shenyang City, Liaoning, China. ${ }^{2}$ Liaoning Key Laboratory of molecular targeted anti-tumor drug development and evaluation, China Medical University, No.77 Puhe Road, Shenyang North New Area, 110122 Shenyang City, Liaoning, China. ${ }^{3}$ Section of Hematology/ Oncology, Department of Medicine, University of Chicago, Chicago, IL 606371463, USA

\section{Conflict of interest}

The authors declare that they have no conflict of interest.

\section{Publisher's note}

Springer Nature remains neutral with regard to jurisdictional claims in published maps and institutional affiliations.

Supplementary Information accompanies this paper at (https://doi.org/ 10.1038/s41419-019-1871-z).

Received: 19 December 2018 Revised: 15 July 2019 Accepted: 15 July 2019 Published online: 11 September 2019

\section{References}

1. Ferlay, J. et al. Cancer incidence and mortality worldwide: sources, methods and major patterns in GLOBOCAN 2012. Int. J. Cancer 136, E359-E386 (2015).

2. Austreid, E., Lonning, P. E. \& Eikesdal, H. P. The emergence of targeted drugs in breast cancer to prevent resistance to endocrine treatment and chemotherapy. Expert Opin. Pharmacother. 15, 681-700 (2014).

3. Kandoth, C. et al. Mutational landscape and significance across 12 major cancer types. Nature 502, 333-339 (2013).

4. Freed-Pastor, W. A. \& Prives, C. Mutant p53: one name, many proteins. Genes Dev. 26, 1268-1286 (2012)

5. Aas, T. et al. Specific P53 mutations are associated with de novo resistance to doxorubicin in breast cancer patients. Nat. Med. 2, 811-814 (1996).

6. Borresen, A. L. et al. TP53 mutations and breast cancer prognosis: particularly poor survival rates for cases with mutations in the zinc-binding domains. Genes, chromosomes cancer 14, 71-75 (1995).

7. Kuptsova-Clarkson, N. et al. XPD DNA nucleotide excision repair gene polymorphisms associated with DNA repair deficiency predict better treatment outcomes in secondary acute myeloid leukemia. Int. J. Mol. Epidemiol. Genet. 1, 278-294 (2010).

8. Pitroda, S. P., Bao, R., Andrade, J., Weichselbaum, R. R. \& Connell, P. P. Low recombination proficiency score (RPS) predicts heightened sensitivity to DNAdamaging chemotherapy in breast cancer. Clin. Cancer Res. 23, 4493-4500 (2017).
9. Polotskaia, A. et al. Proteome-wide analysis of mutant p53 targets in breast cancer identifies new levels of gain-of-function that influence PARP, PCNA and MCM4. Proc. Natl Acad. Sci. USA 112, E1220-E1229 (2015).

10. Esquela-Kerscher, A. \& Slack, F. J. Oncomirs - microRNAs with a role in cancer. Nat. Rev. Cancer 6, 259-269 (2006).

11. Vandenberg, C. J. et al. BRCA1-independent ubiquitination of FANCD2. Mol. Cell 12, 247-254 (2003).

12. Uchiyama, M., Terunuma, J. \& Hanaoka, F. The protein level of Rev1, a TLS polymerase in fission yeast, is strictly regulated during the cell cycle and after DNA damage. Plos One 10, e0130000 (2015).

13. Yao, C. et al. The Fanconi anemia/BRCA pathway is involved in DNA interstrand cross-link repair of adriamycin-resistant leukemia cells. Leuk. Lymphoma 56, 755-762 (2015).

14. Tommasino, F. et al. Induction and processing of the radiation-induced gamma-H2AX signal and its link to the underlying pattern of DSB: a combined experimental and modelling study. PlOS ONE 10, e0129416 (2015).

15. Markova, E., Schultz, N. \& Belyaev, I. Y. Kinetics and dose-response of residual 53BP1/gamma-H2AX foci: co-localization, relationship with DSB repair and clonogenic survival. Int. J. Radiat. Biol. 83, 319-329 (2007).

16. Bunz, F. et al. Disruption of p53 in human cancer cells alters the responses to therapeutic agents. J. Clin. Investig. 104, 263-269 (1999).

17. Duffy, M. J., Synnott, N. C. \& Crown, J. Mutant p53 as a target for cancer treatment. Eur. J. Cancer 83, 258-265 (2017).

18. Zhao, D., Tahaney, W. M., Mazumdar, A., Savage, M. I. \& Brown, P. H. Molecularly targeted therapies for p53-mutant cancers. Cell. Mol. life Sci. 74, 4171-4187 (2017).

19. Geisler, S. et al. TP53 gene mutations predict the response to neoadjuvant treatment with 5-fluorouracil and mitomycin in locally advanced breast cancer. Clin. Cancer Res. 9, 5582-5588 (2003).

20. Knappskog, S. et al. Concomitant inactivation of the p53- and pRB- functional pathways predicts resistance to DNA damaging drugs in breast cancer in vivo. Mol. Oncol. 9, 1553-1564 (2015).

21. Geisler, S. et al. Influence of TP53 gene alterations and c-erbB-2 expression on the response to treatment with doxorubicin in locally advanced breast cancer. Cancer Res. 61, 2505-2512 (2001).

22. Bertheau, P. et al. Effect of mutated TP53 on response of advanced breast cancers to high-dose chemotherapy. Lancet 360, 852-854 (2002).

23. Chrisanthar, R. et al. Predictive and prognostic impact of TP53 mutations and MDM2 promoter genotype in primary breast cancer patients treated with epirubicin or paclitaxel. PloS ONE 6, e19249 (2011).

24. Jackson, J. G. et al. p53-mediated senescence impairs the apoptotic response to chemotherapy and clinical outcome in breast cancer. Cancer Cell $\mathbf{2 1}$ 793-806 (2012).

25. He, C., Li, L., Guan, X., Xiong, L. \& Miao, X. Mutant p53 gain of function and chemoresistance: the role of mutant p53 in response to clinical chemotherapy. Chemotherapy 62, 43-53 (2017).

26. Su, X.\& Huang, J. The Fanconi anemia pathway and DNA interstrand cross-link repair. Protein Cell 2, 704-711 (2011).

27. Shukla, P., Solanki, A., Ghosh, K. \& Vundinti, B. R. DNA interstrand cross-link repair: understanding role of Fanconi anemia pathway and therapeutic implications. Eur. J. Haematol. 91, 381-393 (2013).

28. Leveille, F. et al. The Fanconi anemia gene product FANCF is a flexible adaptor protein. J. Biol. Chem. 279, 39421-39430 (2004).

29. Li, Y. et al. Gene silencing of FANCF potentiates the sensitivity to mitoxantrone through activation of JNK and p38 signal pathways in breast cancer cells. PloS ONE 7, e44254 (2012).

30. Zhao, L. et al. RNAi-mediated knockdown of FANCF suppresses cell proliferation, migration, invasion, and drug resistance potential of breast cancer cells. Braz. J. Med. Biol. Res. 47, 24-34 (2014).

31. He, M. et al. RNA interference-mediated FANCF silencing sensitizes OVCAR3 ovarian cancer cells to adriamycin through increased adriamycin-induced apoptosis dependent on JNK activation. Oncol. Rep. 29, 1721-1729 (2013).

32. $\mathrm{Yu}, \mathrm{J}$. et al. Silencing of fanconi anemia complementation group $f$ exhibits potent chemosensitization of mitomycin C activity in breast cancer cells. J. Breast Cancer 16, 291-299 (2013).

33. Kim, H., Yang, K., Dejsuphong, D. \& D'Andrea, A. D. Regulation of Rev1 by the Fanconi anemia core complex. Nat. Struct. Mol. Biol. 19, 164-170 (2012).

34. Wojtaszek, J. L. et al. A small molecule targeting mutagenic translesion synthesis improves chemotherapy. Cell 178, 152-159.e111 (2019).

35. Fang, $Y$. et al. Involvement of miR-30c in resistance to doxorubicin by regulating YWHAZ in breast cancer cells. Braz. J. Med. Biol. Res. 47, 60-69 (2014). 
36. Bockhorn, J. et al. MicroRNA-30c inhibits human breast tumour chemotherapy resistance by regulating TWF1 and IL-11. Nat. Commun. 4, 1393 (2013).

37. Lin, X. et al. Bovine embryo-secreted microRNA-30c is a potential non-invasive biomarker for hampered preimplantation developmental competence. Front. Genet. 10, 315 (2019).

38. Zhong, Z., Xia, Y., Wang, P., Liu, B. \& Chen, Y. Low expression of microRNA-30c promotes invasion by inducing epithelial mesenchymal transition in nonsmall cell lung cancer. Mol. Med. Rep. 10, 2575-2579 (2014).

39. Zhong, K., Chen, K., Han, L. \& Li, B. MicroRNA-30b/c inhibits non-small cell lung cancer cell proliferation by targeting Rab18. BMC Cancer 14, 703 (2014).

40. Wu, W. et al. miR-30c negatively regulates the migration and invasion by targeting the immediate early response protein 2 in SMMC-7721 and HepG2 cells. Am. J. Cancer Res. 5, 1435-1446 (2015).

41. Chang, T. C. et al. Transactivation of miR-34a by p53 broadly influences gene expression and promotes apoptosis. Mol. Cell 26, 745-752 (2007).
42. Suzuki, H. I. et al. Modulation of microRNA processing by p53. Nature $\mathbf{4 6 0}$ 529-533 (2009).

43. Junttila, M. R. \& Evan, G. I. p53-a Jack of all trades but master of none. Nat. Rev. Cancer 9, 821-829 (2009).

44. Bieging, K. T., Mello, S. S. \& Attardi, L. D. Unravelling mechanisms of p53mediated tumour suppression. Nat. Rev. Cancer 14, 359-370 (2014).

45. $\mathrm{Bi}$, J. et al. miR-181a induces macrophage polarized to $\mathrm{M} 2$ phenotype and promotes M2 macrophage-mediated tumor cell metastasis by targeting KLF6 and C/EBPalpha. Mol. Ther. Nucleic Acids 5, e368 (2016).

46. Wang, Y. et al. MicroRNA-138 modulates DNA damage response by repressing histone H2AX expression. Mol. Cancer Res.: MCR 9, 1100-1111 (2011).

47. Suresh, B. et al. Regulation of Fanconi anemia protein FANCD2 monoubiquitination by miR-302. Biochemical biophysical Res. Commun. 466, 180-185 (2015).

48. Kumaravel, T. S. \& Jha, A. N. Reliable Comet assay measurements for detecting DNA damage induced by ionising radiation and chemicals. Mutat. Res. 605, 7-16 (2006). 